\title{
Climate Change and Health: More Research Is Still Needed
}

\section{Ho-Jang Kwon}

Department of Preventive Medicine, Dankook University College of Medicine, Cheonan, Korea

It is common knowledge that climate change negatively affects human health. Climate change can increase the risk of high temperature-related diseases, diseases associated with air pollution, vector-borne diseases, allergies, and other conditions. The World Health Organization estimates that approximately 250000 elderly people will die each year between 2030 and 2050 from exposure to heat waves, diarrhea, malaria, dengue fever, and coastal flooding [1].

The most direct effect of climate change is disease caused by heat waves. Korea experienced its worst recorded heat wave in 2018, during which 4526 people were reported to have heatrelated illnesses (HRI) and 48 people died of those illnesses, according to a real-time tally administered by the Korea Centers for Disease Control and Prevention through an emergency room monitoring system [2]. However, the number of confirmed deaths from HRI reported by the National Statistical Office a year later was much higher (147 people), and the conditions of those with underlying diseases also worsened due to the heat wave. Thus, the excess mortality is estimated to be even higher than that reported by the National Statistical Office [3].

The experience of the worst heat wave to date spread the social perception that heat waves are a natural disaster; additionally, heat waves have been categorized as a natural disaster in the Framework Act on the Management of Disasters and

Received: January 6, 2020 Accepted: January 14, 2020

Corresponding author: Ho-Jang Kwon, MD, PhD

Department of Preventive Medicine, Dankook University College of

Medicine, 119 Dandae-ro, Dongnam-gu, Cheonan 31116, Korea

E-mail: hojangkwon@gmail.com

This is an Open Access article distributed under the terms of the Creative Commons Attribution Non-Commercial License (https://creativecommons.org/licenses/bync/4.0/) which permits unrestricted non-commercial use, distribution, and reproduction in any medium, provided the original work is properly cited.
Safety. Because the heat wave was officially recognized as a natural disaster, deaths from HRI were compensated by the government in the form of damages, while central and local governments published manuals on how to cope with heat waves.

Although heat waves have now been recognized as a type of disaster, research is still required on how to create proper countermeasures, as heat waves can lead to several other health issues different from those caused by other weather disasters. According to a survey on the effects of the 2018 heat wave, the health effects that people experienced differed significantly depending on the use of air conditioning [4]. In the future, studies should be conducted on the following aspects of HRI: personal and social risks, the working conditions that render workers susceptible to such conditions, proper guidance for populations that are most vulnerable, and the effects of preventive measures [3].

To effectively implement policy measures promoting adaptation to climate change nationwide, studies should be conducted not only on heat waves but also on the variety of health effects of climate change. Chae and Kim [5], in their systematic review on climate change and its health effects in Korea in this issue, reports that many studies have been conducted on the health effects of climate change, but that few studies are immediately applicable to the process of policy implementation. Furthermore, although many studies on infectious diseases have been conducted, most of these were studies on malaria. In other areas, studies lack enough evidence to establish an agenda item regarding the health impacts of climate change [5].

A recent report published by the Intergovernmental Panel on Climate Change estimated that slightly more than a decade remains in which necessary steps can be taken to effectively reduce carbon dioxide emissions with the goal of limiting the 
global increase in temperature to less than $1.5^{\circ} \mathrm{C}$ in an attempt to prevent catastrophic health outcomes of climate change [6]. Medical professionals should take initiatives to address climate change-associated problems. They should support the development of effective and adaptive strategies to help reduce the health risks of climate change, and they should promote healthy lifestyles in line with the reduction of greenhouse gas emissions. Primarily, they should develop scientific evidence to support such efforts by conducting further research on climate change and health.

\section{CONFLICT OF INTEREST}

The author has no conflicts of interest associated with the material presented in this paper.

\section{FUNDING}

None.

\section{ACKNOWLEDGEMENTS}

None.

\section{AUTHOR CONTRIBUTIONS}

All work was done by HJK.

\section{ORCID}

Ho-Jang Kwon https://orcid.org/0000-0002-9774-0480

\section{REFERENCES}

1. World Health Organization. Quantitative risk assessment of the effects of climate change on selected causes of death, 2030s and 2050s; 2014 [cited 2020 Jan 1]. Available from: https://www.who.int/globalchange/publications/quantitative-risk-assessment/en/.

2. Korea Centers for Disease Control and Prevention. Analysis of heat-related illness surveillance in 2018. Public Health Wkly Rep 2019;12(20):630-638 (Korean).

3. Kim DW, Kwon C, Kim J, Lee JS. Characteristics of heat waves from a disaster perspective. J Prev Med Public Health 2020; 53(1):26-28.

4. Lee YH, Bae S, Hwang SS, Kim JH, Kim KN, Lim YH, et al. Association between air conditioning use and self-reported symptoms during the 2018 heat wave in Korea. J Prev Med Public Health 2020;53(1):15-25.

5. Chae SM, Kim D. Research trends in agenda-setting for climate change adaptation policy in the public health sector in Korea. J Prev Med Public Health 2020;53(1):3-14.

6. Intergovernmental Panel on Climate Change. Special report: global warming of $1.5^{\circ} \mathrm{C}$ [cited 2020 Jan 1]. Available from: https://www.ipcc.ch/sr15/. 